\title{
BMJ Open Complex challenges for patients with protracted incurable cancer: an ethnographic study in a comprehensive cancer centre in the Netherlands
}

\author{
Hilde M Buiting, ${ }^{1}$ Marleen A C van Ark, ${ }^{1,2}$ Otto Dethmers, ${ }^{3}$ Emma P E Maats, ${ }^{1,4}$ \\ Jogien A Stoker, ${ }^{5,6}$ Gabe S Sonke ${ }^{1}$
}

To cite: Buiting HM, van Ark MAC, Dethmers 0, et al. Complex challenges for patients with protracted incurable cancer: an ethnographic study in a comprehensive cancer centre in the Netherlands. BMJ Open 2019;9:e024450. doi:10.1136/ bmjopen-2018-024450

- Prepublication history for this paper is available online. To view these files please visit the journal online (http://dx.doi org/10.1136/bmjopen-2018024450).

Received 12 June 2018 Revised 24 January 2019 Accepted 31 January 2019

Check for updates

(C) Author(s) (or their employer(s)) 2019. Re-use permitted under CC BY-NC. No commercial re-use. See rights and permissions. Published by BMJ.

For numbered affiliations see end of article.

Correspondence to

Dr Hilde M Buiting;

h.buiting@nki.nl

\section{ABSTRACT}

Objective Advances in oncology increasingly result in protracted disease trajectories for patients with incurable cancer. In this disease phase, patients are aware of the incurable nature of cancer although they are not yet approaching the last phase of life. We explored the challenges for patients confronted with protracted incurable cancer. Design Ethnographic study (2015-2017) based on conversations with patients, observations at a day-care unit and a selection of information from the medical records of patients who died during the study period. Setting The day-care unit of a comprehensive cancer centre in the Netherlands.

Participants Nineteen patients with stage IV breast cancer (in remission, $>1$ year after diagnosis) and 11 patients with stage IV lung-cancer (in remission, $>6$ months after diagnosis). Results In patients who had died during the study period, the treatment response often fluctuated between stable, remission and progression throughout the course of the disease. Patients reported that this fluctuation could be overwhelming. However, as patients grew accustomed to having protracted incurable cancer, the distress associated with fluctuations (perceived in scan results) slowly faded. Patients reported that cancer became part of who they were. At the day-care unit, most patients talked about their disease in an optimistic or neutral way and expressed delight in life. They often expressed gratefulness for the possible prolongation of life, expressed hope and tried to stay optimistic. This was frequently reinforced by optimistic doctors and nurses. Relatives, however, could downplay such optimism. Moreover, some patients acknowledged that hope was qualified by their personal challenges regarding their disease.

Conclusions In situations where tumours remained in remission or were stable for extended periods, patients grew accustomed to having cancer. At the day-care unit, medical professionals typically encouraged an attitude of being hopeful and optimistic, which could be downplayed by relatives. More research is warranted to explore this protracted disease phase and this optimistic view among healthcare professionals.

\section{INTRODUCTION}

Advances in oncology have resulted in protracted disease trajectories in incurable
Strengths and limitations of this study

- This is the first study that qualitatively explores the impact of living with protracted incurable cancer.

- This study covered a long time period (2015-2017) and could therefore show that the patient's condition fluctuates during the period in which patients are diagnosed with incurable cancer.

- This study combined observations, short conversations with patients (and relatives) and medical record data to gain in-depth insight into this protracted disease phase.

- A limitation of the study is that the conversations were sometimes brief and that results with respect to communication with patients may be different in other (non-specialised) cancer hospitals as hospital cultures differ.

- The average age of the patients was quite high and there were relatively few men, probably reflecting different experiences with respect to protracted incurable cancer between men and women.

cancer patients. ${ }^{1}$ Accordingly, it is sometimes argued that some forms of cancer seem to be turning into a chronic disease. ${ }^{2-4}$ Surprisingly, little information is available as yet about experiences with protracted incurable cancer. ${ }^{5}$ However, given the extended periods of survival, patients with protracted incurable cancer may benefit from either survivorship interventions ${ }^{6}$ (ie, the approach for addressing long-term needs of cancer survivors) or palliative or supportive care interventions. ${ }^{7}$ Studies focusing on the last phase of life or on advanced cancer in general may help provide some ideas. ${ }^{89}$ Intense fear about death, fatigue, uncertainty about the prognosis, and hope for recovery have been shown to be rather important. ${ }^{10-12}$ Plausibly, the same topics may be relevant for patients with protracted incurable cancer. Whether and to what extent is not yet clear. 
Little has been written on how these protracted disease trajectories are challenging the ability of patients to cope with the disease. Walshe et al, however, have reported on successful coping strategies for patients living with advanced cancer, illustrating the importance of focusing on patients' personal coping strategies. ${ }^{13}$ Moreover, Roberts and his colleagues also discussed coping strategies in advanced cancer, focusing on either a 'problem-focused' or 'emotion-focused' therapy. ${ }^{14}$ In contrast, much has been written about the novel cancer therapeutics themselves. ${ }^{15-17}$ During the last couple of years, new mutations have been recovered in patients with lung cancer (EGFR), breast cancer (BRCA1, BRCA2 and HER2) and several other cancers, resulting in the development of new genotype-directed therapy throughout the patient's disease course. Increased prognostic uncertainty on the part of clinicians, however, complicates prognostic communication with patients, and accordingly certainty among patients. ${ }^{18}$ As a result, this changing landscape in treatment options will obviously raise new (ethical) dilemmas for patients as well as healthcare professionals.

Our project started from the observation that patients living with protracted incurable cancer are inadvertently overlooked. In this specific study, we spoke with patients (and their close relatives) at the day-care unit and focused on the challenges in this specific disease phase.

\section{METHODS}

\section{Design and setting}

This study is part of a larger project that examines the experiences, needs and wishes of patients with protracted incurable cancer and their healthcare professionals, using a mixed methods ethnographic design. For this study, a qualitative database was used in which the experiences, needs and wishes of patients with protracted incurable cancer were collected. Data collection started in 2015. It consisted of short conversations with patients at the day-care unit and in-depth interviews in the hospital or home setting, as well as some interviews with bereaved family members. Over the years, topics were added to the interviews and conversations, depending on the discussions that were taking place at that time. A Consolidated Criteria for Reporting Qualitative research checklist was used to make sure the qualitative research was of an appropriate standard.

We purposefully chose this design to ensure that the results would ultimately be practice driven and connect closely to medical practice. ${ }^{19}$ A specific strength of ethnography lies in its ability to communicate details plotted in experiences of illness and care. ${ }^{20}$ In the present study, we combined participant observation with (informal) conversations to build in-depth understanding about the practice of incurable cancer (explicitly and implicitly) and how healthcare professionals and patients experience long-standing incurable cancer within the context of daily medical practice. Since this is a relatively new research area, we established a definitional framework beforehand (see table 1).

\section{Recruitment and sampling \\ Observations}

Observational research started in July 2015. In the first phase, field notes were made in the 'backstage' regions of practice (eg, general locations such as waiting rooms) to generate knowledge about how and why patients and healthcare professionals behave as they do. HMB sat with, observed and sometimes accompanied healthcare professionals.

In the second phase, observation moved to the "front stage'- that is, doctor-patient encounters and direct interviews with patients. In this phase, more detailed observations were made and described in observational field notes. Apart from the research questions for the main study, HMB focused on the following topics during the observations: the atmosphere, emotions, mood (patient/ personal reflections), language use, interaction between patients and healthcare professionals; and answers associated with the research questions.

Observational field notes were compiled on the observation days $(\mathrm{n}=21)$.

\section{Short conversations}

From July 2015 onwards, short conversations were held at the day-care unit of a comprehensive cancer hospital in the Netherlands. These conversations were considered least disturbing for the patient because they were already at the location anyway. Furthermore, they were less likely to be affected by any specific event, such as receiving good/bad news after a consultation with their treating doctor. Only lung-cancer patients who had been diagnosed with stage IV disease at least 6 months previously and breast-cancer patients who had been diagnosed with stage IV disease at least 1 year previously were selected.

In total, 30 patients were approached at the day-care unit by HMB, a female researcher in social sciences with many years of interview experience. All patients were approached at times when HMB was at the hospital and had time to talk to them. Patient selection was therefore random. All patients were given an information sheet about the study, including background information on the researcher who carried out the interviews. Before approaching a patient, HMB checked with the nurses at the day-care unit whether it would be appropriate to do so. In three cases, the nurses advised her not to approach patients because they had just received bad news. HMB had not seen any of the patients before the start of the conversations at the day-care unit.

The short conversations had an open frame. We purposefully chose not to use a large topic list, and we openly asked how patients felt about living with protracted incurable cancer. Often, the conversation started with their disease history and possible unmet needs. As the study progressed, we asked more specifically about patients' quality of life. We did not initiate specific topics, such as 
Table 1 Definitional framework

\section{The disease}

\section{Disease phases}

Chronic disease/chronic cancer According to the National Institute for Public Health and the Environment (In Dutch: RIVM), a chronic disease is a disease with irreversible prospects and with a relatively long disease course. Chronic diseases are different from other diseases in that these patients are care-dependent for a very long time. ${ }^{40}$ Cancer is also categorised as a chronic disease.

In medical oncology, there is a major debate as to whether cancer should be viewed as a chronic disease or not, while healthcare professionals do not want to provide unrealistic prognoses. This also holds for patients with protracted incurable cancer.

Protracted incurable cancer We define protracted incurable cancer as a disease phase where patients receive cancer treatment such as immune therapy, hormonal treatment or chemotherapy, and whereby the disease can be considered stable or in remission for long periods of time.

During this period, the patient's physical condition may sometimes go up and down due to treatment side-effects. In other words, although the response to treatment/the patient's condition can be considered stable or in remission for long periods, briefer periods of progression also occur.

\section{The patient}

States associated with living with cancer Optimism

Optimism is all about anticipating a positive future. To be optimistic means that we expect things to go our way. ${ }^{41}$ Optimists are aware that positive outcomes are dependent on their own efforts.

It should however be noted that optimism is partly inherited, and certain patients are more easily able to choose to be optimistic (eg, deliberate optimism).

$\begin{array}{ll}\text { Hope } & \begin{array}{l}\text { As opposed to optimism, hope generally focuses on a specific goal, such as hope for a } \\ \text { longer life. }{ }^{42} \text { It contrasts with hopelessness/powerlessness, and is much more about how } \\ \text { you feel. It is also argued that emotions go beyond the mere 'feeling' of that emotion; } \\ \text { emotions are a way in which we interact with the world, and accordingly, hope is } \\ \text { sometimes defined as an emotional attitude. }{ }^{25}\end{array} \\ & \begin{array}{l}\text { Research about cancer patients' fear is extensive. In the context of protracted incurable } \\ \text { cancer, fear of cancer recurrence is commonly studied. }{ }^{43} \text { It is often characterised by } \\ \text { chronic worry, excessive body checks and difficulties with making future plans. }\end{array} \\ \text { Uncertainty } & \begin{array}{l}\text { There has also been a great deal of research on uncertainty. } \\ \text { in }{ }^{21} \text { In essence, uncertainty } \\ \text { involves the inability to attribute meaning to events. }\end{array}\end{array}$

Our aim wasnot to explore a specific concept but to conceptualise some definitions of terms that often came up during conversations .

positivity and fear, and only focused on such items if they were brought up by the patient himself or herself.

We continued conversations with patients until data saturation was reached with respect to the research questions of this specific study. In some cases, we asked patients whether they would be willing to continue in another interview. These interviews are, however, not included in this study, although MvA participated in five of those interviews to attain a clearer view of the dilemmas of this specific patient group.
The median length of the audio-recorded conversations at the day-care unit was $10 \mathrm{~min}$ (see table 2). Conversations ended due to circumstances (such as the end of the chemotherapy regimen); because patients simply wanted to stop talking; or because they had nothing more to say. Patients received a short information letter with contact details about the study before a conversation was started. None of the patients refused to participate. In eight cases, a close relative of the patient (often the partner) was present as well. The conversations of the 30 patients were

Table 2 Patient and interview characteristics

\begin{tabular}{llllll}
\hline & $\boldsymbol{n}$ patients & $\begin{array}{l}\text { Mean time length } \\
\text { (SD) (minutes) }\end{array}$ & $\begin{array}{l}\text { Median time } \\
\text { length (minutes) }\end{array}$ & $\begin{array}{l}\text { Minimum } \\
\text { (minutes) }\end{array}$ & $\begin{array}{l}\text { Maximum } \\
\text { (minutes) }\end{array}$ \\
\hline Short conversations $^{1}$ & 30 & $13(9)$ & 10 & 2 & 39 \\
\hline
\end{tabular}

Short conversations were held at the day-care unit, while patients received their chemotherapy regimen. Conversations that were held during the observation days $(n=12)$ are not included, and they were recorded in field notes only. 


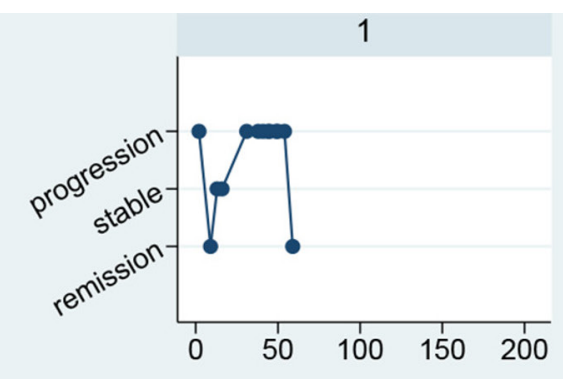

5

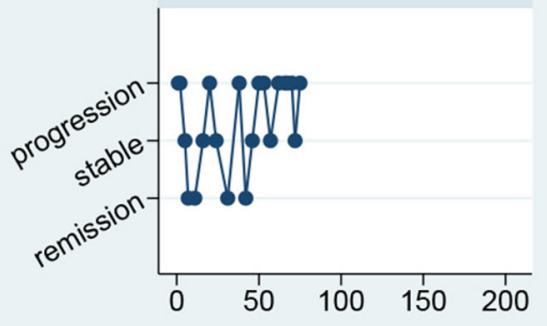

9

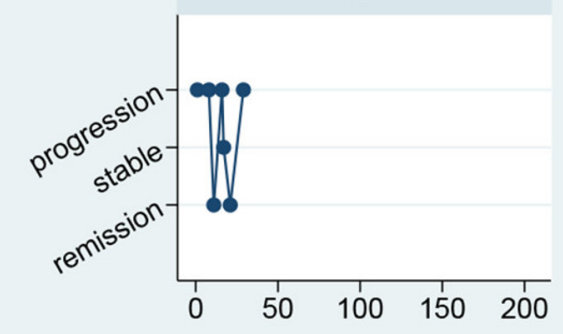

2

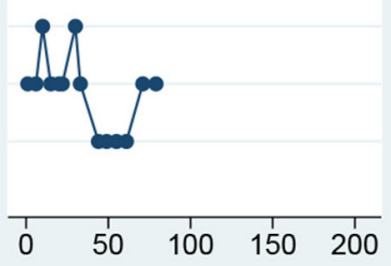

6

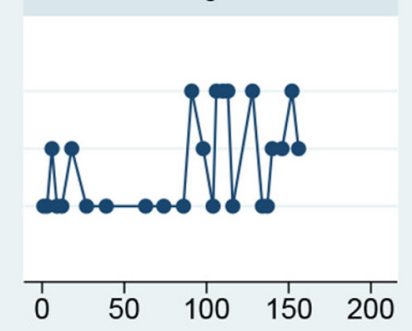

10

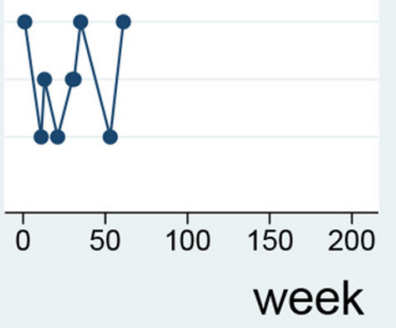

3

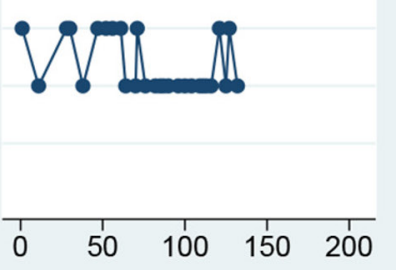

7

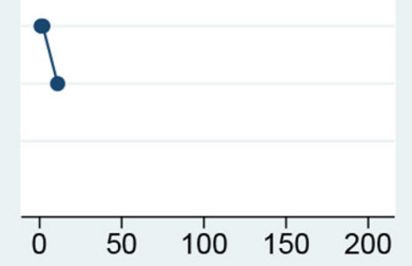

11

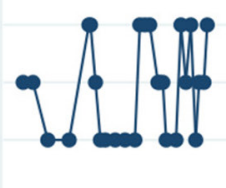

\begin{tabular}{lllll}
\hline & 50 & 100 & 150 & 200
\end{tabular}

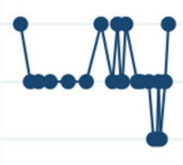

8

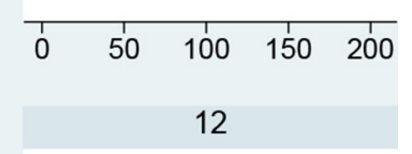

Graphs by Patient

Figure 1 Patients' response to treatment as described in their medical status during the consultations with the treating doctor as documented during the time, the patient visited the hospital. Each graph depicts one patient who died during the study period $(n=12)$.

audio-recorded and transcribed verbatim (see table 2). The transcripts were not returned to the participants for comments.

\section{Medical record data}

We collected medical record data of 12 patients whose conversation was audio-recorded $(\mathrm{n}=30)$ and who had died $(n=12)$ by the end of 2016 . We recorded the disease status (eg, stable, remission and progression) at the time of each appointment with the treating doctor and plotted these data over time in figures for every single patient (see figure 1). The disease status was obtained from the doctors' notes of the consultations. Their conclusion about the disease status was mostly based on a comparison of tumour markers and/or radiological findings with those in the previous visit.

\section{Patient and public involvement}

The research questions for this specific study were inspired by problems we noticed while working in or observing actual medical practice. Thus, the research questions were-by definition-inspired by problems experienced by the patients themselves. We did not involve patients in the design of the study. However, during recruitment and the execution of the study we did ask patients about possible suggestions to further improve the study. Finally, we intend to send our study participants a publication with our results at the end of the study.

\section{Data analysis}

All conversations and observations were coded and analysed using the programme Atlas-ti V.8.2. We (MvA and $\mathrm{HMB}$ ) read through 12 conversations separately at different times to search for themes. These themes were discussed to check for interpreter consensus. Subsequently, a scheme was developed to index text fragments with similar content (in Atlas-ti V.8.2). In analysing the themes, hypotheses emerged and were checked against the data.

Although the conversations were performed by one researcher only, we ensured appropriate analysis of the data by involving at least two researchers and holding proper discussions about the findings with several project members. MvA subsequently developed a tabular grid to organise interview information from each individual patient regarding the following themes: support from the patient's surroundings, physical complaints, uncertainty, 
an indication of the prognosis, how the patient seemed to deal with the final phase of life, daily life, and some space for notable aspects in either content or language use. Furthermore, descriptive information was added to the table concerning the date and duration of the interview, sex, age, type of cancer, location of the interview and the attendees. Other members of the team (OD, JAS, GSS) participated in the analysis by commenting on previous versions of the Results section.

All the authors evaluated whether the final quotes were used in the right (medical) context. According to Dutch policy, the study did not require a formal review by an ethics committee because the content of the interviews and observations was not considered to be potentially incriminating. However, we asked the medical ethics committee of our hospital to provide us with a declaration of no objection (In Dutch: Verklaring van geen bezwaar) confirming that our medical ethics committee had seen the study and had provided local approval to carry out the study, a process in accordance with local ethics regulations. Before starting a conversation, we provided the patient with information and asked them for permission to audio-record this conversation so as to be able to use accurate quotes in the final manuscripts. We sent a lay version of our results to the participants who were still alive; the participants could contact the researcher to comment on this or ask for clarification.

The following conventions are used to distinguish in the text between different types of data collection and technique: all data collected by observation are presented in the text in italics; all data collected from audio-recordings are presented in the text in quotation marks and in italics.

A professional translator translated the quotes that we chose to illustrate our results.

\section{RESULTS}

\section{Quantitative findings}

Of the 30 patients, 24 were women $(80 \%)$ and six were men $(20 \%)$. In this specific study sample, 19 patients experienced some form of breast cancer (63\%) and 11 patients experienced some form of lung cancer (37\%). The disease trajectory of patients who died during the study period is depicted in figure 1 . The patient's response to treatment often fluctuated between stable and either remission or progression. The disease period of patients in this specific hospital varied from approximately 30 to 130 weeks.

\section{Qualitative findings}

In the conversations that we held with patients at the day-care unit, three different themes were identified: their uncertainty about the prognosis in this protracted disease trajectory, their intention to stay hopeful, and the influence of others in staying hopeful and finding a new balance.
On and on: facing death versus surviving

Patients' and relatives' uncertainty seemed to be the overarching theme in the majority of the conversations that we held with patients at the day-care unit. The unpredictability of treatment response seemed to interfere with patients' ability to attribute meaning to activities, and accordingly achieve certainty. This was expressed either explicitly or implicitly but always revealed two sides of the same coin, that is, patients seemed to be hopeful and fearful at the same time. Being aware of the incurable nature of their disease also brought out those two sides of the same coin.

R2 (partner): Sure, I think you've touched on a key aspect here [...] there is no path to full recovery, at least that's what they actually said at a certain point. $[\ldots]$

R: Personally, I call it bad and stable.

I: Right.

R: Yes, stable, but we know that it's no longer $100 \%$ curable... but it could take a very long time yet.

I: Right, it could be stable for a very long time.

R2: Yeah, and then I reckon the aim is to just take the right approach to let you do as many things as possible that you want to do.

\section{Patient 16, 2016 (breast cancer)}

Sometimes, the patient's fear predominated. Despite being in a stable condition, those patients experienced chronic stress from the fear that cancer would recur. Patients seldom complained, but it could however paralyse them and prevent them from doing other activities. For these patients, the frequent consultations at the hospital could be both burdensome and enlightening at the same time.

Yes, I think I'm someone who soon sees the gloomy side. Well, of course that's annoying. That's not good. Then you think... then you've had a CT scan and you have to wait another week for the results and then you think: 'Oh, I can feel something here, could that be why?' And then, well, today you get the message that it hasn't grown. So, you've spent a week worrying about nothing really. Patient 5, 2016 (lung cancer)

Often, the patient's hope predominated, especially in situations where they had grown accustomed to having incurable cancer. Although most patients said they knew that their disease could not be cured any more, they often refused to focus on the incurable nature of their disease. They wanted to stay positive and retain autonomy. One patient, for instance, reported that she did not want to wait for the next scan results, but preferred to do something herself to retain some form of autonomy, partly in order to stay positive. She explained, for instance, that she was very conscious about what she ate, as she was convinced that too much sugar could have a negative impact on tumour growth. This positive and hopeful 
attitude sometimes decreased if patients had undergone multiple forms of oncological treatment, and/or the response to treatment had been disappointing. Still, patients said that they were clinging onto hope.

I: Is it because there is less response right now, that you are more often thinking about your disease?

R: I don't know, but the heaviness... You do spend a very long time with this feeling that one day we'll win this battle, whether that's justified or not.

\section{Patient 3, 2016 (breast cancer)}

Having a seemingly short life expectancy made patients conscious that all occasions could be for the last time, which could be distressing even if this turned out not to be the case (because new treatment options were offered). Prolongation of life was welcomed on the one hand, but on the other hand it gave them less security as their future life was rather uncertain.

But then I came back, partly with the idea that this time I'll do things completely differently. We won't start making preparations any more, or more or less say goodbye or go along to every birthday party, celebrating in style because it might be your last time. But it drives you crazy if you're constantly having to say goodbye. Patient 1, 2015 (lung cancer)

Apart from the mental challenge, patients' experiences of physical discomfort sometimes resulted in uncertainty too. Patients could become extremely worried if they felt pain somewhere in their body, immediately thinking of cancer growth or (more) metastases. Other patients explained that they no longer trusted their bodily sensations at all as the diagnosis of cancer was something, they would not have expected beforehand either. Being a stranger to your own body increased the sense of uncertainty and, accordingly, negatively affected patients' well-being.

Sure, and then you go to the hospital and you think, well, I feel good, it's all going well and... But it turns out it's not going well and then you just lose your confidence in your body completely. Patient 25, 2015 (breast cancer)

\section{Staying hopeful and optimistic}

In this day-care setting, where nurses sometimes had to rush through the chemotherapy regimen, the atmosphere could be described as positive and energetic. Nurses said that they lacked time for deeper, time-consuming conversations. Yet they were friendly, greeted patients they knew from previous visits and joked a lot. 'I just need to check your birth date' (and they ran to the next patient), 'Are you cold? I'll get another blanket for you. A hot water bottle may be even better (I use them too when we go camping) but that's not working here' (and they rushed away). This positive and informal atmosphere seemed to impact both healthcare professionals and the visitors at the unit. In this way, the atmosphere at the day-care unit seemed to encourage positive feelings and thoughts. Some patients reported that having conversations about the last phase of life would be too burdensome at this day-care unit.

'I guess that if conversations here (at the day-care unit) were to particularly focus on the approaching death, conversations would be more burdensome. So no, it's OK like this.' Patient 31 (breast cancer)

Apart from being hopeful, patients also explained how they intended to stay optimistic, for example, how they really tried to believe in what they hoped for. For instance, they (rationally) argued that they could start worrying once their prognosis got much worse. Some patients tried to look at their situation in a positive/optimistic way, for instance by viewing every visit to the hospital as a 'day out'. Compared with being hopeful, being optimistic could be viewed as a more active/rational approach. In some situations, patients decided to make decisions against their doctors' advice, such as asking for a second opinion. In doing this, their optimism could be regarded as a coping strategy.

No, I don't spend much time thinking about it [approaching death] because that would drive you crazy, I reckon. Still enjoy life a bit and be with the children for as long as that's still possible, and when it's no longer possible, there will still be plenty of time for sackcloth and ashes. At least that's how I see it, or want to see it [laughs], right.

\section{Patient 24, 2015 (breast cancer)}

Compared with being hopeful, being optimistic more often seemed to be a real choice. However, this was much easier for some patients than for others. Patients who found being optimistic easier also found it easier to accept their fate and cope with the disease. Moreover, those patients seemed to be more receptive to good news, which immediately resulted in a happy and relaxed mood and euphoric reactions.

It's great, I am just so happy that... she said it [the cancer] won't go away completely... but she can't really say anything about that. But what happened now was overwhelming. [patient just heard about their excellent response to treatment] Patient 21, 2015 (breast cancer)

\section{The influence of others and finding a new balance}

Other people could have an important role as well in whether patients were either hopeful or optimistic. Healthcare professionals could be of tremendous importance in either downplaying or increasing patient's hope as well as their optimistic attitude to life. Although patients appreciated doctors' commitment, they sometimes doubted whether the information they had just received was adequate. Open communication about the fact that life expectancy could increase (rather than providing a worse prognosis) could also upset patients and make them fearful. 
And if they say 'Well, there is a very small chance that you might possibly recover', you find yourself actually kind of upset and thinking 'Gosh, I was just beginning to get used to the idea that I'm dying and now I suddenly have to start thinking about the future and that kind of thing'. Patient 11, 2016 (breast cancer)

Some patients said that they had previously requested psycho-social support, right after the cancer diagnosis. A majority of the patients further explained that this protracted disease phase was different: they just wanted to continue life, without psycho-social help. Most patients told us that after the big shock of discovering they had cancer, they had slowly found a new life balance with a positive focus.

I remember that I was really struggling with it 4 years ago, when they first diagnosed it. And then I did 'In balance', mainly really for the social welfare, for the social support. And that helped me a great deal to actually get a grip on it. So, things like learning to accept the fact that you'll have to learn to live with the tiredness. And your own mortality and that kind of thing. Patient 11, 2016 (breast cancer)

Most patients explained that after a certain time, the situation of having protracted incurable cancer eventually resulted in acceptation of the disease, which could be interpreted as positive. In this stable disease period (although with fluctuations) patients did not seek any psycho-social help and often felt no need to talk about their disease with close relatives: they regarded their disease as part of who they were. Like the healthcare professionals, they seemed to downplay the situation by making comparisons like 'I've also gone grey in the course of my life'.

It's, I've also gone grey in the course of my life and we never talked about that, I mean, it's just one of those things, that's really the way it is and it's just part of who I am. Like going grey. Patient 26, 2015 (breast cancer)

Nevertheless, it sometimes seemed as if those patients were not as confident as they claimed, for example, some of these patients became emotional during the conversation. Moreover, patients appreciated support from friends and close relatives.

One way or another, he [partner] immediately notices if something isn't going well. But he sits in on all the appointments, he helps in asking questions. [...] I lie here in a hospital bed sleeping part of the day and then waking up, but he still comes along. So even if you can't see him, you know he's waiting for you, you know he's close by. Patient 2, 2017 (lung cancer)

\section{DISCUSSION}

Facing death (progression of the disease) and surviving (remission of the disease) several times could be overwhelming for patients. During these periods, support was greatly appreciated. Most patients grew accustomed to having protracted incurable cancer. The associated fear then slowly faded. As most patients regarded cancer as part of who they were, they generally felt no need to talk about their disease. At the day-care unit, patients frequently adopted a hopeful and optimistic attitude, which was frequently reinforced by optimistic doctors and nurses. Hope often dominated their uncertain lives; fear was present and visible to only a small extent. Partners and close relatives, however, could downplay this optimistic stance.

\section{Strengths and weaknesses}

A previous Dutch ethnographic study focused on the phenomenon of 'false optimism about recovery'. In the waiting room, incurable lung cancer patients rarely appeared to deal with their approaching death, despite their limited life expectancy. ${ }^{19}$ Approximately 20 years later, new cancer therapeutics have changed the landscape in cancer care. We now focused on a new phenomenon, that is, 'Patients' challenges while having protracted incurable cancer'. A feature that increases the validity of this study is the long time period (a 2-year study period) and the combination of observations (although not covered in detail here), short conversations with patients (and close relatives) and medical record data. This long time period is important to be able to show that the patient's condition indeed fluctuates and to be able to conduct conversations over a long time-period. Our study also has limitations. First, this study was performed at one cancer centre, and our results may therefore not be representative for the whole cancer population. However, we particularly wanted to focus on patients' challenges while living with protracted incurable cancer and these challenges are probably comparable in other hospitals. Second, the conversations could be very brief. However, since we were particularly interested in patients' perceptions in the day-care setting, this can be considered an inherent part of the ethnographic research. Third, the average age of the patients was quite high and there were relatively few men (because we selected breast-cancer and lung-cancer patients). Fourth, the patients may have given socially desirable answers, because they had close relatives in proximity, and given the absence of a private space. Finally, we focused on the day-care setting only. We purposefully chose to focus on this setting since we were interested in how patients in relatively good condition experienced their disease. Moreover, we were interested as to whether the approach towards patients at the day-care unit could be used in other settings or situations also. We realise however that patients and close relatives may respond rather differently in the home setting, for instance.

\section{Balancing between different degrees of hope and fear}

All the patients in our study experienced uncertainty to some extent in the context of their disease. This is in 
line with previous literature that shows that uncertainty is a common cancer experience that may be related to treatment choices, lack of information and uncertainty in coping with everyday life. ${ }^{112122}$ Our findings, however, contrast with the common cancer disease trajectory, that is, reaching an advanced stage followed by a predictable downhill course over weeks or months. Instead, the disease status of patients with long-standing disease trajectories often went up and down (see also figure 1). As a result, it is understandable that levels of fear and hope will go up and down too. ${ }^{23}$

Apart from uncertainty due to ongoing fluctuations between stable status, remission and progression, a new element is uncertainty about the possibility that new treatment options will be developed in time. Some patients had already given up hope for a longer life and had merely accepted that they would die. This could be explained by the fact that patients' wish to live decreases and their wish to die increases when nearing death, since their acceptance of death grows. ${ }^{24}$ Now, this natural dying process was to a certain extent disrupted. Yet other characteristics of protracted incurable cancer gave room for hope. As patients grew accustomed to having incurable cancer, they learnt more about their responses to their disease, and accordingly what they hoped for. Interestingly, what patients' value may change or come to be prioritised differently, and accordingly, also what they hope for. A discussion paper by Simpson ${ }^{25}$ argues that in situations where people find it hard to imagine what their life could be like, it is difficult to hope. This is in accordance with what patients experienced in our study. Opening up the discussion about future treatment options may decrease uncertainty, and increase the patient's hope.

\section{Using optimism in the context of protracted incurable cancer}

Choosing to be optimistic seemed to be an effective coping strategy, according to the patients in our study. An optimistic or hopeful approach is in line with what many medical oncologists also believe is the right way to go: although an objective positive effect on disease progression has not been shown, instilling hope in patients has previously been shown to have an effect on how patients try to maintain their weight, take their medications, and so on as was shown in a discussion paper. ${ }^{26}$ This paper further showed that maintaining optimism is considered one of the essential elements of meaningful medical practice. Although hopefulness for medical oncologists, especially in the academic/research settings, is often grounded in the biomedical dimensions of their work, it has been shown to be worthwhile. The paper further suggests that the optimistic stance of the nurses in our study may be effective.

In general, the balance among feelings relates to differences in optimism, that is, positive feelings (like being hopeful) relate to positive thinking (like being optimistic) ${ }^{27}$ Some patients in our study reported that their confidence and positive feelings grew throughout the disease course in situations where treatment appeared to have a real effect on the tumour. Carver et al suggests that an optimistic life stance is more susceptible to change during times of transition and/or when outcomes become uncertain. ${ }^{28}$ Our study suggests that optimism did indeed change in uncertain situations, at least in most of the patients we spoke with at the day-care unit of this specific hospital.

Yet it should be noted that optimism as a coping strategy was probably relatively easy because all patients were in relatively good physical condition. Moreover, patients might have given socially desirable answers. A previous study, for instance, showed that cancer patients receiving palliative care can be remarkably optimistic in the hospital or in their satisfactory relationship with the nursing staff. ${ }^{29} 30$ These findings are also in line with our data that show that nearly all patients wanted to be optimistic, although fear [fear of cancer recurrence (FCR)] was sometimes overriding and/or close relatives said something different. Perhaps optimism is frequently used as the initial coping strategy, but if fear and uncertainty predominate, other coping strategies need to be used as well.

\section{Conclusions and implications for policy}

This explorative ethnographic study can be considered a first step towards discovering how recent developments in cancer will shape clinical and research domains in the context of protracted incurable cancer and chronic disease management, including definitions regarding the curative/palliative dichotomy. By providing insight into the social dynamics of healthcare, our study may increase awareness about the current developments in the care of patients with protracted incurable cancer. ${ }^{31}$

Our study shows that patients with protracted incurable cancer have different experiences to some extent to patients with a common palliative trajectory. ${ }^{32}$ Their physical and mental status often fluctuated, partly because of unpredictable responses to cancer treatment. ${ }^{33}$ Instead of slow physical deterioration, our patients at a certain point grew accustomed to a stable situation and accepted the minor physical symptoms ('like going grey').

Our results provide entry points in how patients with protracted incurable cancer could be assisted and cared for, taking into account their personal coping strategies as well as possible interventions that might benefit those patients.

More research is warranted to explore whether optimism, as a common care approach by nurses, is sufficient to guarantee a good and meaningful life in these patients. If patients (and their close relatives) were better able to show resilience, ${ }^{34}$ this could increase their well-being. Yet account needs to be taken of the fact that such a positive life stance may not be what everyone wishes. ${ }^{35}$ Moreover, avoiding negative emotions is not always realistic or desirable.

More research is warranted about patients' values and wishes in this protracted disease phase. The use of advanced care planning is recommended these days, ${ }^{36}$ 
but it is also known that expressing values and wishes for the next stage/disease period can be difficult. ${ }^{32}$ Yet patients in a stable disease phase, as is often the situation in protracted incurable cancer-will probably be able to formulate life goals for the present stage. ${ }^{33} 37$ This might be more helpful than encouraging these patients to think about their approaching death only, although this aspect should not be neglected. Such an approach is probably also more in line with survivorship care approaches, such as light therapy against cancer-related fatigue, ${ }^{38}$ or the long-term cognitive effects of some forms of cancer treatment. ${ }^{39}$

\section{Author affiliations}

${ }^{1}$ Medical Oncology, Netherlands Cancer Institute, Amsterdam, The Netherlands ${ }^{2}$ Clinical Psychology, Department of Behavioural and Movement Sciences, VU University, Amsterdam, The Netherlands

${ }^{3}$ Oncology day-care unit, Netherlands Cancer Institute, Amsterdam, The Netherlands ${ }^{4}$ University Medical Center Utrecht, Utrecht, The Netherlands

${ }^{5}$ Medical Psychology, Netherlands Cancer Institute, Amsterdam, The Netherlands

${ }^{6}$ Centre of Quality of Life, Netherlands Cancer Institute, Amsterdam, The Netherlands

Acknowledgements The authors first of all gratefully thank all patients and relatives for their participation and openness during the conversations. The authors would further like to thank Mrs M Verheul for transcribing part of the conversations. Moreover, they gratefully acknowledge $\mathrm{Dr} \mathrm{K}$ Jozwiak for assistance in the analysis of the medical record data. They would further like to thank Dr P Brown for his helpful articles concerning hope. Finally, they would like to thank all the nurses at the day-care unit, who have been of great assistance.

Contributors HMB designed the study. HMB, MACvA and EPEM carried out the study. HMB, MACVA, OD, EPEM, JAS and GSS were involved in the interpretation of the study findings. HMB and MACVA wrote the manuscript, which was critically read by all the authors. HMB is the guarantor of the study. All authors had full access to all the data in the study and can take responsibility for their integrity and the accuracy of their analysis.

Funding This work was supported by an unrestricted grant of Janssen and a grant from Ars Donandi.

Competing interests None declared.

Patient consent for publication Not required.

Ethics approval The study did not require review by a medical ethical committee because the observations and short talks were not considered to be possibly incriminating for patients/relatives.

Provenance and peer review Not commissioned; externally peer reviewed.

Data sharing statement All data relevant to the study are included in the article or uploaded as supplementary information.

Open access This is an open access article distributed in accordance with the Creative Commons Attribution Non Commercial (CC BY-NC 4.0) license, which permits others to distribute, remix, adapt, build upon this work non-commercially, and license their derivative works on different terms, provided the original work is properly cited, appropriate credit is given, any changes made indicated, and the use is non-commercial. See: http://creativecommons.org/licenses/by-nc/4.0/.

\section{REFERENCES}

1. Bishop AJ, Ensor J, Moulder SL, et al. Prognosis for patients with metastatic breast cancer who achieve a no-evidence-of-disease status after systemic or local therapy. Cancer 2015;121:4324-32.

2. Buiting HM, Linn SC, Smorenburg $\mathrm{CH}$, et al. [Living with incurable cancer]. Ned Tijdschr Geneeskd 2016;160:A9615.

3. Harley C, Pini S, Bartlett YK, et al. Defining chronic cancer: patient experiences and self-management needs. BMJ Support Palliat Care 2015:5:343-50.

4. McCorkle R, Ercolano E, Lazenby M, et al. Self-management: Enabling and empowering patients living with cancer as a chronic illness. CA Cancer J Clin 2011;61:50-62.
5. Fadul N, Elsayem A, Palmer JL, et al. Supportive versus palliative care: What's in a name? Cancer 2009;115:2013-21.

6. Aaronson NK, Mattioli V, Minton O, et al. Beyond treatment Psychosocial and behavioural issues in cancer survivorship research and practice. EJC Suppl 2014;12:54-64.

7. Bakitas M, Lyons KD, Hegel MT, et al. Effects of a palliative care intervention on clinical outcomes in patients with advanced cancer: the Project ENABLE II randomized controlled trial. JAMA 2009;302:741-9.

8. Brom L, Pasman HR, Widdershoven GA, et al. Patients' preferences for participation in treatment decision-making at the end of life: qualitative interviews with advanced cancer patients. PLoS One 2014;9:e100435.

9. Buiting HM, Rurup ML, Wijsbek $\mathrm{H}$, et al. Understanding provision of chemotherapy to patients with end stage cancer: qualitative interview study. BMJ 2011;342:d1993.

10. Halkett GKB, Lobb EA, Oldham L, et al. The information and support needs of patients diagnosed with High Grade Glioma. Patient Educ Couns 2010;79:112-9.

11. Shaha M, Cox CL, Talman K, et al. Uncertainty in Breast, Prostate, and Colorectal Cancer: Implications for Supportive Care. Journal of Nursing Scholarship 2008:40:60-7.

12. Ashbury FD, Findlay H, Reynolds B, et al. A Canadian survey of cancer patients' experiences: are their needs being met? J Pain Symptom Manage 1998;16:298-306.

13. Walshe C, Roberts D, Appleton L, et al. Coping Well with Advanced Cancer: A Serial Qualitative Interview Study with Patients and Family Carers. PLoS One 2017;12:e0169071.

14. Roberts D, Calman L, Large $P$, et al. A revised model for coping with advanced cancer. Mapping concepts from a longitudinal qualitative study of patients and carers coping with advanced cancer onto Folkman and Greer's theoretical model of appraisal and coping Psychooncology 2018;27:229-35.

15. Blank CU, Haanen JB, Ribas A, et al. Cancer immunology. The "cancer immunogram". Science 2016;352:658-60.

16. Smit EF, Wu Y-L, Gervais R, et al. A randomized, double-blind, phase III study comparing two doses of erlotinib for second-line treatment of current smokers with advanced non-small-cell lung cancer (CurrentS). Lung Cancer 2016;99:94-101.

17. Temel JS, Gainor JF, Sullivan RJ, et al. Keeping Expectations in Check With Immune Checkpoint Inhibitors. J Clin Oncol 2018;36:1654-7.

18. LeBlanc TW, Temel JS, Helft PR. "How Much Time Do I Have?": Communicating Prognosis in the Era of Exceptional Responders. Am Soc Clin Oncol Educ Book 2018;38:787-94.

19. The AM, Hak T, Koëter G, et al. Collusion in doctor-patient communication about imminent death: an ethnographic study. BMJ 2000;321:1376-81

20. Livingstone J. Improvising medicine. An African oncology ward in an emerging cancer epidemic. 2015.

21. Etkind SN, Bristowe K, Bailey K, et al. How does uncertainty shape patient experience in advanced illness? A secondary analysis of qualitative data. Palliat Med 2017;31:171-80.

22. Nelson JP. Struggling to Gain Meaning: Living with the Uncertainty of Breast Cancer. Advances in Nursing Science 1996;18:59-76.

23. Karlsson M, Friberg F, Wallengren C, et al. Meanings of existentia uncertainty and certainty for people diagnosed with cancer and receiving palliative treatment: a life-world phenomenological study. BMC Palliat Care 2014;13:28.

24. Lichtenthal WG, Nilsson M, Zhang B, et al. Do rates of mental disorders and existential distress among advanced stage cancer patients increase as death approaches? Psychooncology 2009;18:50-61.

25. Simpson C. When Hope Makes Us Vulnerable: A Discussion of Patient-Healthcare Provider Interactions in the Context of Hope. Bioethics 2004;18:428-47.

26. del Vecchio Good M-J, Good BJ, Schaffer C, et al. American oncology and the discourse on hope. Cult Med Psychiatry 1990;14:59-79.

27. Janssen $E$, van Osch L, Lechner L, et al. Thinking versus feeling: Differentiating between cognitive and affective components of perceived cancer risk. Psychol Health 2012;27:767-83.

28. Carver CS, Scheier MF, Segerstrom SC. Optimism. Clin Psychol Rev 2010;30:879-89.

29. Cameron J, Waterworth S. Patients' experiences of ongoing palliative chemotherapy for metastatic colorectal cancer: a qualitative study. Int J Palliat Nurs 2014;20:218-24.

30. McCreaddie M, Payne S, Froggatt K. Ensnared by positivity: A constructivist perspective on 'being positive' in cancer care. European Journal of Oncology Nursing 2010;14:283-90. 
31. Stellmach D, Beshar I, Bedford J, et al. Anthropology in public health emergencies: what is anthropology good for? BMJ Glob Health 2018;3:e000534.

32. Buiting HM, Terpstra W, Dalhuisen F, et al. The Facilitating Role of Chemotherapy in the Palliative Phase of Cancer: Qualitative Interviews with Advanced Cancer Patients. PLoS One 2013;8:e77959.

33. Simpkin AL, Schwartzstein RM. Tolerating Uncertainty - The Next Medical Revolution? N Engl J Med Overseas Ed 2016;375:1713-5.

34. Molina Y, Yi JC, Martinez-Gutierrez J, et al. Resilience among patients across the cancer continuum: diverse perspectives. Clin $\mathrm{J}$ Oncol Nurs 2014;18:93-101.

35. Hartogh Gden, Den Hartogh G. Suffering and dying well: on the proper aim of palliative care. Med Health Care Philos 2017;20:413-24.

36. Rietjens JAC, Sudore RL, Connolly M, et al. Definition and recommendations for advance care planning: an international consensus supported by the European Association for Palliative Care. Lancet Oncol 2017;18:e543-e551.

37. Maas M, Beets-Tan RGH, Lambregts DMJ, et al. Wait-and-See Policy for Clinical Complete Responders After Chemoradiation for Rectal Cancer. Journal of Clinical Oncology 2011;29:4633-40.
38. Starreveld DEJ, Daniels LA, Valdimarsdottir HB, et al. Light therapy as a treatment of cancer-related fatigue in (non-)Hodgkin lymphoma survivors (SPARKLE trial): study protocol of a multicenter randomized controlled trial. BMC Cancer 2018;18:880.

39. Menning S, de Ruiter MB, Veltman DJ, et al. Changes in brain white matter integrity after systemic treatment for breast cancer: a prospective longitudinal study. Brain Imaging Behav 2018;12:324-34.

40. Vonk R, Korevaar JC, van Saase L, et al. Een samenhangend beeld van kanker: ziekte, zorg, mens en maatschappij. Thema Rapportage van de Staat van Volksgezondheid en Zorg: RIVM 2016.

41. Mendiburo-Seguel A, Páez D, Martínez-Sánchez F. Humor styles and personality: A meta-analysis of the relation between humor styles and the Big Five personality traits. Scand J Psychol 2015;56:335-40.

42. Olsman E, Leget C, Duggleby W, et al. A singing choir: Understanding the dynamics of hope, hopelessness, and despair in palliative care patients. A longitudinal qualitative study. Palliat Support Care 2015;13:1643-50.

43. Thewes $\mathrm{B}$, Husson $\mathrm{O}$, Poort $\mathrm{H}$, et al. Fear of cancer recurrence in an era of personalized medicine. J Clin Oncol 2017:Jco2017728212. 